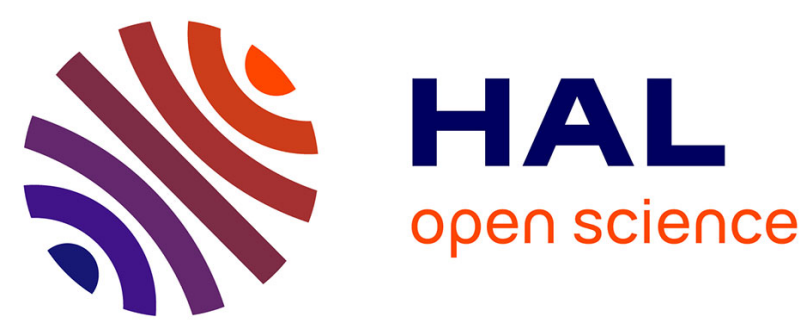

\title{
Flower of Life, Six-Fold Symmetry and Honeycomb Packing of Circles in the Mycenaean Geometry
}

\author{
Amelia Carolina Sparavigna, Mauro Maria Baldi
}

\section{To cite this version:}

Amelia Carolina Sparavigna, Mauro Maria Baldi. Flower of Life, Six-Fold Symmetry and Honeycomb Packing of Circles in the Mycenaean Geometry. 2016. hal-01303108

\section{HAL Id: hal-01303108 \\ https://hal.science/hal-01303108}

Preprint submitted on 15 Apr 2016

HAL is a multi-disciplinary open access archive for the deposit and dissemination of scientific research documents, whether they are published or not. The documents may come from teaching and research institutions in France or abroad, or from public or private research centers.
L'archive ouverte pluridisciplinaire HAL, est destinée au dépôt et à la diffusion de documents scientifiques de niveau recherche, publiés ou non, émanant des établissements d'enseignement et de recherche français ou étrangers, des laboratoires publics ou privés. 


\title{
Flower of Life, Six-Fold Symmetry and Honeycomb Pack- ing of Circles in the Mycenaean Geometry
}

\author{
Amelia Carolina Sparavigna ${ }^{1}$ and Mauro Maria Baldi ${ }^{2}$ \\ 1 Department of Applied Science and Technology, Politecnico di Torino, Torino, Italy \\ 2 Department of Control and Computer Engineering, Politecnico di Torino, Torino, Italy \\ Email: amelia.sparavigna@polito.it, mauro.baldi@polito.it
}

Submitted SSRN 29/03/2016

\begin{abstract}
In this paper we discuss the geometric decoration of some Mycenaean artifacts, having a remarkable six-fold symmetry, probably suggested by the observation of the natural form of the honeycomb of beehives. In particular, we will discuss a decoration of a gold roundel, made by means of a compass, that looks like the Flower of Life of sacred geometry.
\end{abstract}

Keywords: Sacred geometry, Geometry, History of Science, Geometric Patterns, Compass Constructions, Archaeology, Mycenaean Civilization.

Subject Areas: Archeology, History of Science, History of Geometry.

\section{Introduction}

It had been observed in [1], that the sacred geometry, the discipline ascribing symbolic and sacred meanings to regular geometric shapes and proportions [2,3], has its roots in the study of nature and in the mathematical principles we can obtain from it. Therefore, some of the geometric forms we find in nature are interpreted as fundamental by this discipline and, as explained in [4], relevant as further proofs of the natural significance of geometric forms. One of these forms is the honeybees construct of hexagonal cells made of wax to support the life of the colony. It is probable that the observation of this natural geometry originated several symbols having hexagonal form or a six-fold rotational symmetry. Among then, we find the design of the Flower of Life.

In this paper, our aim will be that of showing a possible link of the honeycomb layout of some icons found in the decorations of artifacts of Mycenaean civilization to rituals connected to honey-bees. Here, we will discuss some of these icons; one looks like a Flower of Life, another one is representing a honey bee and others have a geometric six-fold symmetry and honeycomb packing of circles. Probably, a sort of "sacred geometry" was used by Mycenaean people to create these icons. In fact, we aim adding the adjective "sacred" to a geometry that had been already discussed in a remarkable paper, which analyzed the evolution of geometric patterns in ancient Europe [5].

Before our discussion on the artifacts of the ancient Aegean civilization of Mycenae, we want to shortly remember a feature of honeycomb geometry, the existence of the so-called Hexagonal Honeycomb Conjecture. This conjecture states that the honeycomb hexagonal grid is the best way to divide a surface into regions of equal area with the least total perimeter [6]. The conjecture was proven in 1999 by Thomas C. Hales, but the problem of the form chosen by bees for their home was quite older. It was first given by Marcus Terentius Varro, 36 BC, in his book on agriculture. As told in [7], Varro is writing about the bee's honeycomb telling that there were two competing theories for the existence of such hexagonal structure. One theory told that hexagons are the better geometry for accommodating the bee's six feet, but Varro considered this hypothesis questionable. The other theory is that the hexagonal shape is the most efficiently one for subdividing the space in little units, so that 
honeycombs created by bees are using the least amount of wax. These structures are then explained by an isoperimetric property of the hexagonal honeycomb [6,7]. In fact, Hales proved a conjecture which is related to the densest circle packing of the plane, where every circle is tangent to six other circles, filling over $90 \%$ of the area of the plane [6].

Let us start our discussion on old Mycenaean civilization and geometry. The most amazing artifact that we will see in this paper will be that depicting the Flower of Life, which required a remarkable skill of the artist that made it. Before discussing this icon, let us shortly talk about Mycenaean civilization.

\section{Mycenaean civilization}

It was a civilization of the late Bronze Age, from 15th to 13th century BC, that had influence on the Peloponnese, and cross-correlations with the islands of Aegean Sea, in particular with Crete and the Cyclades [8]. Then, the Mycenaean people were influenced by the Minoan civilization which had its main center at Knossos, Crete. The major Mycenaean centers included Mycenae and Tiryns, and other places of ancient Greece [8]. According to [8], large palace complexes existed at most of the Mycenaean centers. These complexes had important architectural features in common. In fact, the complexes were built around a large rectangular central hall, the Megaron, that was the heart of the palace and also the throne room of the ruler. A second smaller hall, many private apartments and areas, dedicated to administration offices, storage and manufacturing were present in the palace. Let us remember that in the Tiryns palace we can see the use, for the floors of the palace, of concrete too [9]. Moreover, as shown in [10], the Mycenaean architects used the geometrical proportions of both Perfect (Pythagorean) and Quasi-Perfect combinations of integers.

The Mycenaean civilization had trading contact with other Aegean cultures, as shown by the presence of foreign goods in Mycenaean settlements such as gold, ivory, copper and glass and by the discovery of Mycenaean goods such as pottery in places as far afield as Egypt, Mesopotamia, the Levant, Anatolia, Sicily and Cyprus [8]. As told in [8], perishable goods such as oil and wine were significant Mycenaean exports. Let us also add to goods given in [8], the honey produced by bees. In art, the Mycenaean artisans had a tendency to schematic representations, in a new style that became the dominant one throughout the Mediterranean. However, the Mycenaean civilization ended during the Bronze Age Collapse around 1200 BC [8], that originated the so-called ancient Dark Ages. Many centuries had been necessary, before "Greek culture would have again the heights of the late Bronze Age" [8].

\section{Schliemann's excavations}

As explained in [11], the first excavations at Mycenae were carried out by Greek archaeologist Kyriakos Pittakis in 1841. He found and restored the Lion Gate. In 1874, Heinrich Schliemann (1822-1890) started excavating deep shafts over the acropolis without permission; in 1876, a complete excavation commenced with the permission of the Archaeological Society of Athens. Schliemann, who believed in the historical truth of the Homeric stories, when discovered a skull beneath a gold death mask in one of the Mycenaean tombs, declared he had "gazed upon the face of Agamemnon" [11]. For this reason, the tomb is known as the Agamemnon's tomb. Since Schliemann's day, more scientific excavations have taken place at Mycenae, mainly by Greek archaeologists but also by the British School at Athens.

For our discussion on the Mycenaean geometry, we use the book entitled "Mycenae: a narrative of researches and discoveries of Mycenae and Tiryns", that Heinrich Schliemann published in 1878, available at archive.org, https://archive.org/details/mycenaenarrativ00schl.

This book and its illustrations give us a panoramic view of the variety and complexity of geometric decorations. Here we will concentrate in particular on the hexagonal geometry, which was probably suggested to Mycenaean people by the natural honeycomb structure. 


\section{The Flower of Life}

Shaft Grave III, in the Grave Circle A, known as the 'Grave of the Women,' contained three female and two infant interments [12]. Women were literally covered in gold jewelry with massive gold diadems, while the infants were overlaid with gold foil. As explained in [12], a great number of gold roundels and other gold cut-out foils, having various shapes, with repousse decorations on them, were attached to bodies' clothes or shrouds. Let us consider one of the roundels. It is given in the Figure 1; left-upper panel is reproducing an illustration of the Schliemann's book.
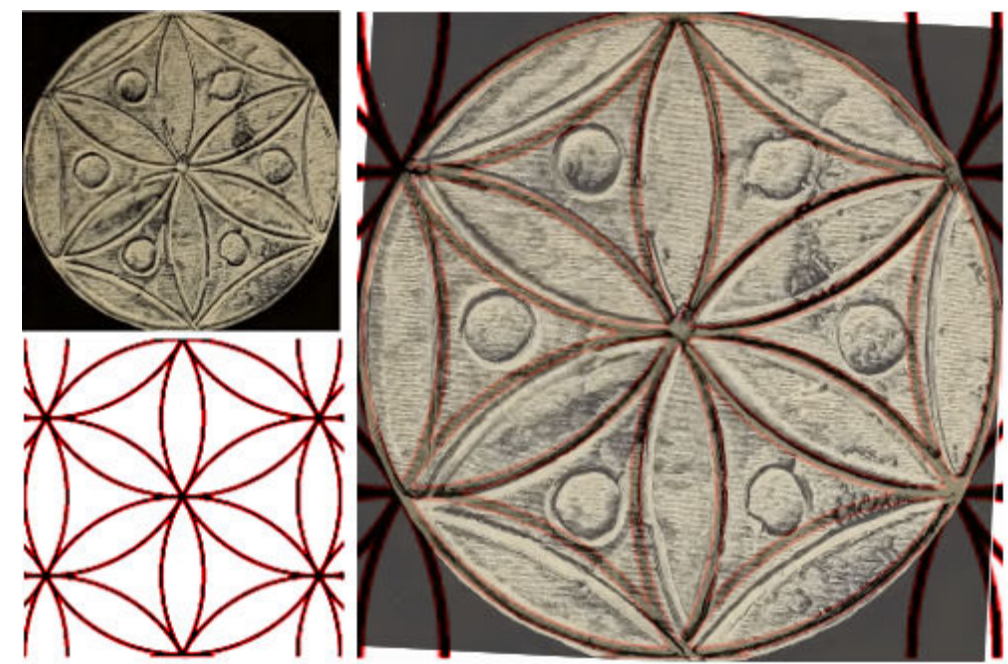

Figure 1. Gold roundel from Mycenae compared to the Flower of Life. On the right, the two images have been combined using GIMP, the GNU Image Manipulation Program for X Windows systems.

In the Figure 1 we see the roundel compared to the Flower of Life, made using a compass. On the right, we see the two images combined with GIMP. Concerning this roundel and other artifacts of Grave Circle A, in [5] the author notes that the geometry "differs in character, not only from the Middle Cycladic and Minoan but also from the Old European style, concerned as the latter had been with visual impression, often geometrically regular at the level of immediate perception but imprecise below that. The gold roundel of \#38 (Fig.1) may serve to highlight this difference. The circular edge is made by means of a compass (by leaving the central point unerased, the artist has taken care that we do not overlook this fact); so are the circular arcs drawn inside it. The pattern is the one which arises when you try to structure the whole plane homogeneously by means of a compass with constant opening ..., or when you draw longer arcs than needed during the construction of a regular hexagon. Even if not concerned with any kind of scientific geometry, the pattern of the roundel is more mathematical in its geometry than anything we have seen thus far, representing a systematic exploration of the properties of the circle. Exact measurement also shows that the six small circles are centred precisely with respect to the equilateral triangles inside which they are drawn" [5]. (Just a comment to a sentence in [5]: also the Minoans had interesting geometric skills [13,14]).

As told in [5], the skilled worker that made the roundel was able of making a curvilinear hexagon using the compass. Let us tell that he was also able of having a regular pentagon as shown by a hexagonal wooden box, a pixis, decorated with gold overlays, that was found in a tomb (Mycenae Shaft Grave V), c.1550-1500 BC from box. The image of this pixis is given at 
the virtual exhibitions of Greek culture at the following link http://nam.culture.gr/portal/page/ portal/deam/virtual exhibitions/EAMP/EAMP808

In [5], the author tells that "the six small circles are centred precisely with respect to the equilateral triangles inside which they are drawn". Of course, these are curvilinear triangles, which can be obtained from the compass construction as given in the Figure 1. Note that, as shown by the superposition of images given in Fig.1, the design of this ancient artifact was highly precise.

\section{Six-fold symmetry and honeycomb packing of circles}

Let us note that the image in the Figure 1 possesses a six-fold symmetry. A rotational symmetry of order $n$, that is the $n$-fold rotational symmetry, with respect to a particular point or axis means that a rotation by an angle of $360^{\circ} / n$ does not change the object. When $n=3$, the angle is $120^{\circ}$ : we find this symmetry in triskelion and Borromean rings. When $n=6$, the angle is $60^{\circ}$. This is the rotational symmetry of hexagons. Besides the Flower of Life, other roundels and decorations of jewels have a remarkable six-fold rotational symmetry. Here we can see some examples in the Figure 2.

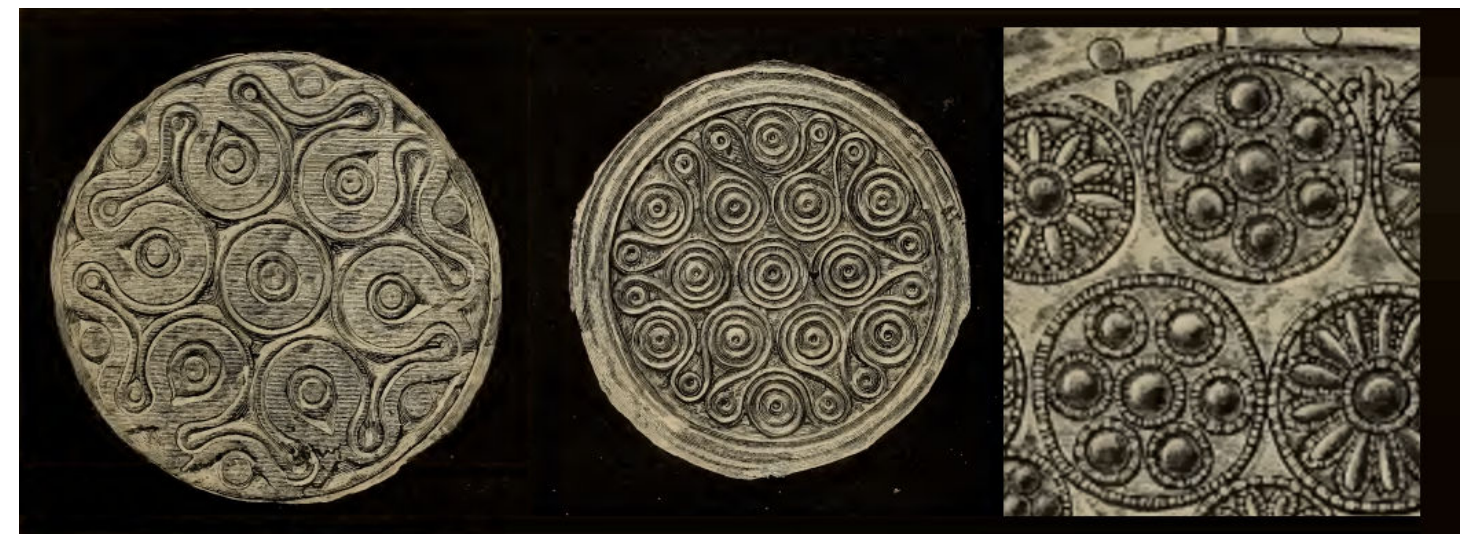

Figure 2. Decorations having a six-fold symmetry (adapted from illustration of the Schliemann's book).

In the Figure 2 we can see also an example of the honeycomb packing of circles. This packing could had been suggested by the honeycomb of beehives; let us remember that inside the cells, healthy larvae coil like a "comma" [15], and grow coiling circularly, as we can see in the picture on the right (Courtesy Waugsberg, Wikipedia. To have this picture, the walls of the cells have been removed. The larvae are about 3 or 4 days old).

In fact, if we consider also the biology of honey bees, we can argue that the roundels could also have, besides their decorative beauty, a symbolic and ritual meaning linked to life.

Some of the roundels seem to have a six-fold symmetry, but in fact, it is a three-fold symmetry. That is, if we rotate the roundel in the Figure 3 of $60^{\circ}$, the image is different. We need to rotate

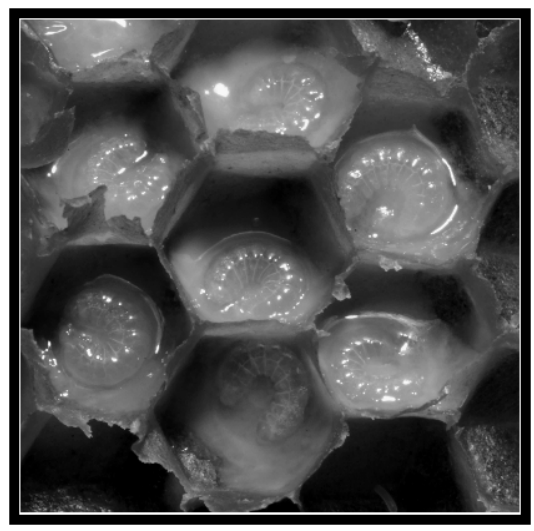
of $120^{\circ}$. Due to the peculiar decoration at the center of the roundel, the decoration does not possess mirror symmetry. It is chiral. Figure 4 gives examples of six-fold symmetry, without mirror symmetry. 

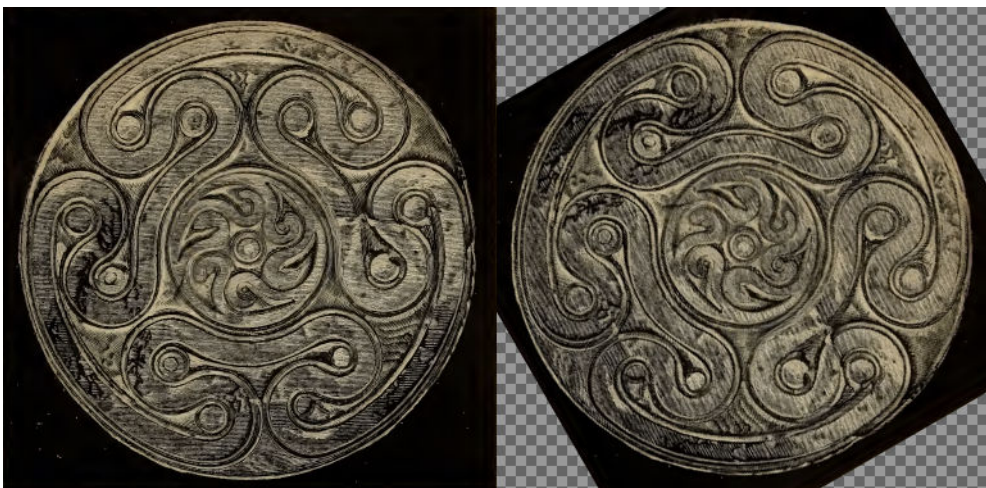

Figure 3. Decoration having a three-fold symmetry. On the right, the image had been rotated of $60^{\circ}$. Note also that this image does not possess a mirror symmetry. It is chiral. The image is adapted from an illustration of the Schliemann's book.

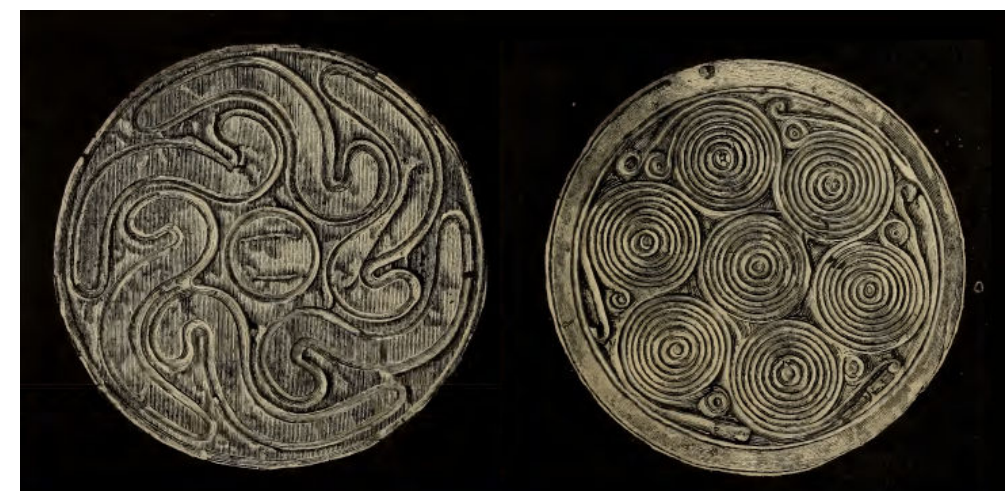

Figure 4. Decoration having a six-fold symmetry. Note that these images do not possess a mirror symmetry The images are from illustrations of the Schliemann's book.

In the Figures 2 and 4 we can see the packing of even circles with the same radius to occupy the space of a circle. For what concerns the packing circles, it was in 1773 that Joseph Louis Lagrange proved that the highest-density lattice arrangement of circles is the hexagonal packing arrangement, in which the centres of the circles are arranged in a hexagonal lattice, like a honeycomb, where circle is surrounded by six other circles.

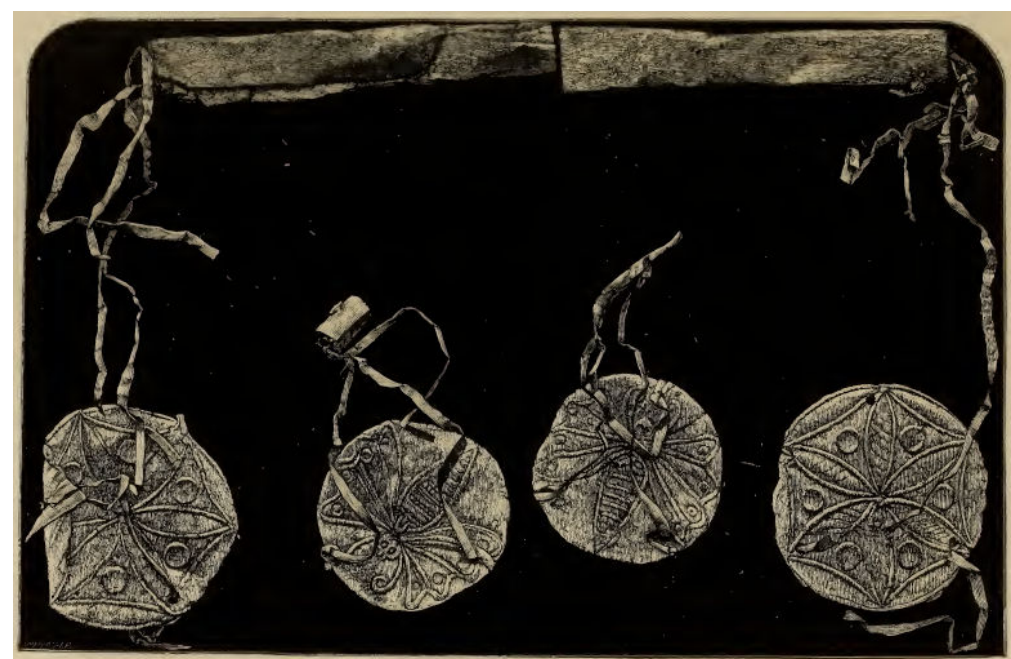

5
Figure 5. Ritual balance from a Mycenaean tomb. The image is obtained from an illustration of the Schliemann's book. Note the Flowers of Life and the roundels decorated with an icon representing a honey-bee. 


\section{Discussion}

The decorations of artifacts found in the Mycenaean tombs had probably a ritual meaning. May be, they were used to protect the person during her/his afterlife, as the scarab seals and other amulets were used in ancient Egypt. Let us note that roundels with the Flower of Life and with an icon representing a honey-bee had been found as plates of balances (see Figure 5). These balances were used just for ritual purposes. This is showing that honey bees were sacred insects with specific importance, like the scarabs, which were representing the sun, in ancient Egypt [16,17]. In fact, in Ancient Aegean cultures, the bee was the emblem of Potnia, a Minoan-Mycenaean Goddess of Animals. The priestesses of Potnia received the name of Melissa, that is honey-bee. Also the priestesses worshipping Artemis and Demeter were Bees [18-20].

Of the religious Mycenaean rituals, burial was an important one as evidenced by the presence of monumental "tholos" tombs, full of precious objects which were buried with the dead [8]. A tholos tomb, also known as beehive tomb, was a structure characterized by a dome created by the superposition of successively smaller rings of stones. The resulting structure resembles a beehive (an ancient one, not a modern one); after the previous discussion of the icons on roundels, it seems probable that the Mycenaean people deliberately used such a shape. Let us stress that the relation between honey bees and humans is a very old one. It started when people learned how to manage them, by providing them with hives, that, in several cases had the form of tholos. According to a research published in 2015 [21], the domestication of bees happened in Anatolia, at least 8,500 years.

Let us consider Figure 5: two of the gold roundels are representing an insect. Let us see it also in the Figure 6.

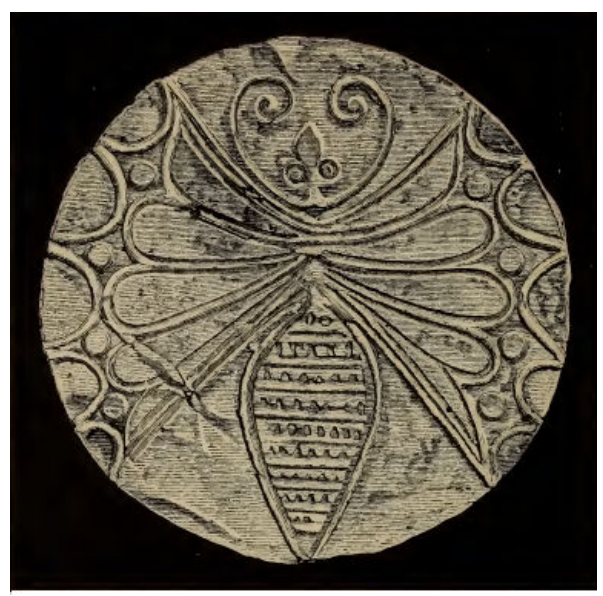

Figure 6. Decoration representing a honey bee. The image is from an illustration of the Schliemann's book.

According to Schliemann, the roundel is representing a butterfly. However, the abdomen is that of a bee, not of a butterfly. Of the geometry of this icon, in [5] it is told that the "bee of \#50 exhibits only a simple mirror symmetry, which is all the motif allows - yet closer inspection of the figure reveals unexpected hidden mathematical regularities ... ; in this sense, the motif only serves as a pretext. Once more, the centre coincides with the foremost point of the abdomen (the only visible part of the body). The abdomen, furthermore, is fitted into the right angle formed by the hind edges of the wings; the front edges of these are curved but approach the prolonged hind edges asymptotically, and the whole configuration is thus determined by a pair of mutually perpendicular axes through the centre of the circle; finally, the insect is provided with ten wings in order to make all this possible". 
In [5] it is told that the motif is only a pretext; however, as we have seen in the previous discussion, the roundels were used in a ritual context, therefore we conclude that the icon and its geometry could had been used to enhance a sacred meaning of it. The Flower of Life and the other icons shown in the paper were probably representing a sort of "sacred geometry", used by Mycenaean people for their rituals.

\section{References}

[1] Skinner, S. (2009). Sacred Geometry: Deciphering the Code. Sterling. ISBN 978-1-4027-6582-7.

[2] Calter, P. Squaring the Circle, Geometry in Art \& Architecture. Wiley

[3] Lawlor, R. (1982). Sacred Geometry: Philosophy and Practice (Vol. 4). New York: Thames and Hudson. ISBN-10: 0500810303, ISBN-13: 978-0500810309

[4] Vv. Aa. (2016). Sacred Geometry. Wikidepia.

[5] Høyrup, J. (2000). Geometrical Patterns in the Pre-Classical Greek Area. Prospecting the Borderland Between Decoration, Art, and Structural Inquiry. Revue d'histoire des mathématiques, 6:5-58.

[6] Vv. Aa. (2016). Honeycomb Conjecture. Wikipedia.

[7] Hales, T. C. (2001). The Honeycomb Conjecture. Discrete and Computational Geometry, 25(1): 1-22. arXiv:math/9906042. doi:10.1007/s004540010071

[8] Cartwright, M. (2013). Mycenaean Civilization, Ancient History Encyclopedia. Last modified May 24, 2013. http://www.ancient.eu /Mycenaean_Civilization/.

[9] Sparavigna, A.C. (2014). Some Notes on Ancient Concrete. International Journal of Sciences, $3(2), 1-6$.

[10] Ranieri, M. (2008). The Pythagorean Geometry of the Atreus Tomb at Mycenae. Archaeologia Baltica, Issue 10, 211-214.

[11] Vv. Aa. (2016). Mycenae. Wikipedia.

[12] Vv. Aa. (2016). http://www.greek-thesaurus.gr/Mycenaean-Grave-Circle-A.html

[13] Papaodysseus, C., Panagopoulos, M., Rousopoulos, P., Galanopoulos, G. and Doumas, C. (2008). Geometric templates used in the Akrotiri (Thera) wall-paintings, Antiquity, 82: 401-408

[14] Sparavigna, A. C. and Baldi, M. M. (2016). A Minoan Geometry for Bisecting and Trisecting the Right Angle. Available at SSRN 2754536.

[15] FAO Corporate Document Repository, http://www.fao.org/docrep/t0104e/t0104e0d.htm

[16] Sparavigna, A. C. (2011). Ancient Egyptian seals and scarabs. Available at http://porto.polito.it/2474784/1/5655978.pdf

[17] Sparavigna, A. C. (2013). The symmetries of the icons on ancient seals. International Journal of Sciences, 2(8), 14-20.

[18] G. W. Elderkin (1939) . The Bee of Artemis. The American Journal of Philology, 60: 203-213.

[19] Neustadt, E. (1906). De Jove cretico, (dissertation, Berlin). Chapter III "de Melissa dea" discusses bee-goddesses and bee-priestesses in Crete.

[20] Harrison, J. E. (1922). Prolegomena to the Study of Greek religion, Princeton university Press.

[21] Roffet-Salque, M., Regert, M., Evershed, R. P. et al. (2015).. Widespread exploitation of the honeybee by early Neolithic farmers. Nature, 527:226-230. doi:10.1038/nature15757 